\title{
Colonialism, science, and health
}

\section{Leonardo Viniegra-Velázquez}

Research Unit in Evidence-Based Medicine, Hematology-Oncology and Research Building, Hospital Infantil de México Federico Gómez, Mexico City, Mexico

\begin{abstract}
In addition to genocide, slavery, and the dispossession of indigenous people, colonialism, as a form of control, meant the suppression of traditional knowledge. The imposition of Christianity, the modern Western paradigm, and modern science that followed perpetrated this suppression. The universal role held by modern science is supported neither by epistemic nor social aspects. It is ineffective and complicit in the collapse of civilization, and it is worsened by comprehensive and unifying ideas to be reduced to an input-process of technological innovation for the benefit of social control industries such as the military, information technology, communication, or health. Furthermore, it suppresses ancestral knowledge related to health and medicine that may be beneficial and must be researched (stimulant medicines). Coupled with the health industry, it promotes the medicalization of life, spreading uncertainty, anxiety, and unease. Therefore, it is an instrument of neocolonialism that imposes its priorities, supplanting problems in subordinated countries, and extracts substantial resources, which is detrimental to social policies and programs. The biggest objection to the universality of modern science is derived from its empiricist and reductionist nature. Through the practically impossible idea of a unifying and explanatory knowledge, it impedes researchers the understanding of the complexity of the world and their historical moment and to act accordingly. It transforms great creative and liberating potential to submissiveness for the interests of capital and its representatives.
\end{abstract}

Key words: Colonialism. Collapse of civilization. Modern science. Reductionism. Disease. Medicalization.

\section{Colonialismo, ciencia y salud}

\section{Resumen}

El colonialismo, como forma de dominación, significó, además de genocidio, esclavitud o despojo de pueblos originarios, la supresión de saberes tradicionales perpetrada por la imposición del cristianismo, del paradigma moderno occidental y de la ciencia moderna que le siguió. El carácter universal detentado por la ciencia moderna no se sostiene en lo epistémico ni en lo social; es inoperante con y cómplice del colapso civilizatorio; se empobrece de ideas comprensivas e integradoras para reducirse al insumo-proceso de la innovación tecnológica en provecho de las industrias del control social (militar, informática, de comunicación o de la salud); y suprime saberes ancestrales de la esfera de la salud que encierran beneficios y posibilidades que es preciso investigar (medicina estimulante). Aunada a la industria de la salud, impulsa la medicalización de la vida, preñándola de incertidumbre, angustia y desasosiego. Es instrumento del neocolonialismo al imponer sus prioridades, que suplantan las propias de los países subordinados y sustraen cuantiosos recursos en detrimento de políticas $y$ programas sociales. La mayor objeción a la universalidad de la ciencia moderna deriva de su carácter empirista y reduc-

\section{Correspondence:}

*Leonardo Viniegra-Velázquez

E-mail: leonardo.viniegra@gmail.com

Available online: 08-06-2020

Date of reception: 12-05-2019

Date of acceptance: 19-02-2020

DOI: 10.24875/BMHIM.20000069
Bol Med Hosp Infant Mex. 2020;77(4):166-177

www.bmhim.com 1665-1146/C 2020 Hospital Infantil de México Federico Gómez. Published by Permanyer. This is an open access article under the CC BY-NC-ND license (http://creativecommons.org/licenses/by-nc-nd/4.0/). 
cionista que, al condicionar la imposibilidad práctica de un conocimiento integrador y explicativo, aleja a los investigadores del entendimiento de la complejidad del mundo, de su momento histórico y de actuar en consecuencia, y transforma la gran potencialidad creativa y liberadora de este enorme contingente en docilidad a los designios de los intereses del capital y sus agentes.

Palabras clave: Colonialismo. Colapso civilizatorio. Ciencia moderna. Reduccionismo. Enfermedad. Medicalización.

"Visible colonialism mutilates you without concealing itself: it forbids you to speak, it forbids you to do and forbids you to be. Invisible colonialism, instead, convinces you that servitude is your destiny and impotence, your nature: it convinces you that you cannot speak, you cannot do, you cannot be." Eduardo Galeano

\section{Introduction}

Why does modern science have a universal monopoly on the truth and sound knowledge and the authority to disqualify "non-scientific" knowledge as false or deceptive? This conception has implied the contempt, exclusion, or perpetual suppression of a vast amount of knowledge that has withstood the test of time and the limiting of immeasurable, irreducible concepts to the spatial and temporal narrowness of experimental settings. The answer needs to be traced back to the time of European expansion to other continents. Ethnic groups were subjugated, plundered, enslaved, decimated, or annihilated. Europeans imposed colonialism along with a Eurocentric worldview, which at that time was led by Christianity, for control ${ }^{1}$. The expansion of capitalism that followed this wave of colonization replaced Christianity. It reconfigured a volatile colonial system in decline, imposing unequal exchange relations on the new formally independent nations that signified a new kind of colonialism and that, with many variations, remains in place until this day. Eurocentric modern science has accompanied the development of capitalism and, in its current phase, reconfigured by mega-corporations, it favors the knowledge inputs of technological innovation required to achieve high-profit margins and for interests of limitless profit dominance? The present paper intends to unveil the relationship between modern science and colonialism, to challenge its universal nature, and to question its role in human progress and, particularly, in the field of health.

\section{Colonialism}

Colonialism, as a form of control, involved not just genocide, submission, enslavement, and dispossession of peoples and nations. Its perpetuation implied an invisible and, therefore, irresistible domination (epigraph). Boaventura de Sousa Santos called it epistemicide $^{3}$ - the discrediting and suppression of traditional local knowledge perpetrated by the imposition of foreign knowledge with claims of universal validity based on Christianity and the emergence of capitalism - which became the modern Western paradigm (MWP) over time: the universal Eurocentric view of the world 1 . The reign of this paradigm was based on the establishment of the dichotomy between modernity and tradition, which allowed the degradation of native peoples' ontologies and the invalidation of non-western knowledge as "traditional," i.e., as the "residue of a past without a future"1. For example, this is revealed in the fact that the systematic study of European society was called sociology and that of non-Europeans was known as ethnography ${ }^{4}$.

The universal power of the MWP is highlighted in the following aspects of history and geography:

a. The qualifiers and timelines that separate the periods of world history - prehistory, ancient, middle, modern, and contemporary ages - are based on European historical evolution and events that shook collective conscience, while the non-European historical experiences are dismissed. Thus, the colonial period, according to a Eurocentric perspective, represented the phase of expansion and diffusion of Western culture and civilization. It was a decisive step to bring uncivilized peoples and nations "back from the backwardness" and concluded with the achievement of independence by American, African, and Asian colonies. In this regard, the theories of colonialism revealed the ethnocidal nature of this form of control that has been perpetuated because, over generations, it convinced the majority of their intrinsic inferiority, of the need to embrace true religion and superior culture, and to integrate themselves into "civilization". This has remained in the unconscious and the imaginary of the formally "independent" populations as a nonjudgmental inclination and openness to "novelties" coming from the 
metropolis, which operate as perennial colonizing influences.

b. In terms of universal geography, it should be noted that Europe, as the center of the world, is a continent apart (for no geographical or geological reason) from those inhabited by "non-Europeans."

Colonialism as a political relationship of domination - subordination that formally disappeared with the "liberation" of the subjugated peoples - has been maintained through cultural, political, and economic forms represented by the empire of the widespread MWP that perpetuated an insensible dominance of the colonizers over the supposedly independent and sovereign states to this day. The MWP has been propagated as the "right way" to interpret history and relate to nature (to use it, and eventually pollute and destroy it). Also, to understand the development of nations as material wealth to the detriment of promotion and protection of all human rights and to define human progress as technological availability (relegating the spiritual, moral, and care aspects of the planetary ecosystem). Furthermore, to exercise power and manage social conflicts through "democracy" (unattainable in capitalism, generating inequalities, and injustices) $)^{6}$. Finally, to resolve conflicts between states through international regulations and institutions (subordinate to imperial powers, they are ineffective in preventing abuse or avoiding perpetual wars). For the central theme of this work, this "correct way" includes monopolizing the production of real and valid knowledge, modern science, with authority to invalidate knowledge lacking scientific support, according to criteria based on an empiricist and reductionist epistemology.

For more than a century, both MWP and modern science have remained indisputable symbols of the superiority of Western civilization, despite two devastating world wars carried out by European countries, which demonstrated the extreme decline of Western civilization. Due to the devastation, the epicenter of MWP moved to the United States, a substantial beneficiary, where degradation continued to be disguised around a "ferocious, cruel, white, racist ethnocentrism," the main perpetrator of the endless wars that mark our era?

\section{The current situation in the world}

A succinct overview of the current situation ${ }^{8}$, which refers to predominant trends and characteristics of the ways of being, acting, coexisting, organizing, and relating of societies and governments in the world and the interaction with the environment ${ }^{\text {, }}$, is subsequently provided. In principle, two distinctive traits in our current form of civilization are emphasized:

(1) The "supreme value" that governs human life is limitless earnings and profit at all costs. Thus, projects involving creativity, ingenuity, solidarity, or generosity that do not contribute to "good business" are invalid, unusual, or dismissed and relegated.

(2) The full commercialization of life has turned human dignity into devalued merchandise that has become expendable, disposable, and a nuisance to survival in an uncertain, degraded, and dangerous world.

These traits are hidden beneath the characteristics that predominate in current societies with many variations, particularly when contrasting colonizing and colonized nations:

a. Social inequality increases to unprecedented extremes. Furthermore, the concentration of socially created material wealth reaches excessive levels.

b. Working conditions are increasingly unstable, uncertain, abusive, and stressful with meager salaries and few rights; the employment outlook for new generations includes insecurity, uncertainty, and unemployment.

c. The circumstances of existence are increasingly adverse for dignified, safe, satisfactory, calm, fraternal, and supportive ways of life.

d. Corruption and crime are becoming widespread under the protection of impunity and discretion, permeating from speculative financial institutions to the low levels of the social underworld.

e. The rules of coexistence that are stipulated in international law are empty rhetoric, and the abuse and dispossession by the strong growth over the weak.

f. Western warmongering with no counterweight raises the risk of nuclear conflict; endless wars are undertaken because they are a lucrative business for "economic health".

g. "Original production" of terrorism by the world's hegemonic powers to undermine and fight enemies and rebels ${ }^{9}$ gets out of control; unprecedented, indiscriminate atrocities that destroy innocent lives and immerse populations in insecurity, uncertainty, anxiety, fear, and despair are perpetrated as a result.

a There are several exceptions to these trends and characteristics, represented mainly by minorities originating from countries that were victims of colonialism, which due to their marginalization and isolation have preserved traditions and, to varying degrees, have been removed from the overwhelming flow of events. 
h. The tragedy of forced migration due to hunger, insecurity, loot, war, or terror spreads and increases to unprecedented levels, aggravated by the exacerbated xenophobia of the destination nations whose governments are responsible for the horrors of this risky migration.

i. The civilization of excessive and wasteful consumption depletes natural resources, severely decimates biodiversity by accelerating the extinction of hundreds of species; and pollutes everything in its path: the atmosphere, oceans, seas, rivers, soil, and even food, secretly and inevitably poisoning us.

j. Extractive industries deprive native populations of their territory, devastate ecosystems, spread pollution everywhere, and are the primary contributors to progressive and irreversible global warming that threatens the viability of life in general and human life in particular. It is clear that this panorama of disasters, adversities, and catastrophes is perceived differently in the public domain and with varied feelings by distinct populations, groups, or individuals mainly due to their place in the framework of social, economic, and political relationships and the degree to which they have been subjected to manipulated media coverage.

This overview leads to an unavoidable diagnosis. Our world, devastated by extreme degradation, is the evidence of the exhaustion and ruin of a civilization controlled by interests of unlimited profit, which has become in merchandise the most sublime and vile of the human condition and profitable business the worst atrocities and devastation on the planet ${ }^{10}$. This diagnosis built on syndromes, symptoms, signs, and indicators of global events in the public domain contrasts with the promising reality of "progress" disseminated by the mass media and with the hope and confidence of the vast majority of the population that we are heading to a better world. It suggests civilizational ruin rather than crisis because we are witnessing the general collapse of values of coexistence as well as spiritual, moral, and ethical values. The degradation is anchored in the subjectivity, where it is perpetuated, and it endures by reaching unprecedented extremes resulting from its global nature and because it is not even perceived as such. Increasingly precarious living conditions, fraught with uncertainty and insecurity, are visible, recognizable, and excruciating conditions resulting from degradation. However, they cover up the heart of the matter: the normalized degeneration of the ways of being, acting, and relating at the local, national, and international levels.

It is worth asking: why do populations with the highest education level in history behave like propitiatory victims of degradation, and why are they mostly indifferent, permissive, or submissive about an unjust, destructive, and cruel nature? The reason is that the ongoing gradual degradation has become a normalized environment that establishes the ethos of Western culture and scientific habitus, which is perpetuated, far from opposed, by schools with few exceptions ${ }^{8}$. At the core of the current ethos, degrading natures are found ${ }^{10}$. 1) Individualism, which implies life projects with the mindset of "everyone for themselves and take what you can," produces people who are numb to and distant from collective interests and demands and oblivious to events that occur beyond the immediate circle, even though they concern all people and are attacks against basic dignity. In the individualistic world, "collective responsibility for the wrongs of society does not exist"11.

2) Reductionism and exclusionary specialization are the predominant concepts behind the division of labor, where specialists have a fragmented and disconnected view of the world. They do not grasp the correlation of the events that shake up and affect it; show disinterest in their historical and social context; demonstrate indifference toward complex and integrative thinking: "the important thing is to be aware of one's field of activity, the rest is a different matter;" and live buried in an individualistic, dark, chaotic, and insecure world.

3)Passivity toward the excesses and abuses of power that crushes rights, with its roots in individualism and the cognitive limitations of exclusionary specialization to which we add the prevailing attitudes of impotence, conformism, fatalism, and abandonment in the face of adversity (colonized nations) or scattered collective responses that are imbued with reactivity and immediacy, not for long-term anticipatory purposes, toward pressing problems (colonizing nations).

4)Competitiveness spurred by a restrictive and uncertain labor market that fosters relationships of rivalry, distrust, or antagonism (not solidarity or fraternity) that aggravate the will to control with its consequences: inequality, abuse, and submission.

5) Consumerism that turns good citizens who exercise their social rights and obligations into good consumers of all kinds of material and symbolic objects to satisfy desires and obsessions or release anxiety and dissatisfaction, which supports an economy that deepens inequalities, exhausts natural resources, and devastates the planet. Consumerism controls consciences and bodies, on the one hand, by polarizing them in the search for identity and a sense of belonging (consumers) and, on the other hand, by leading to dependence on technologies that supplant 
and adulterate intersubjective links and support all kinds of evasive and addictive behaviors.

6)High vulnerability to media manipulation regarding a variety of issues that are unknown to people or that they are indifferent about, at a time when the media mostly controls everything, with disinformation and convictions that align consciences and bodies with unlimited for-profit interests or that are destabilizing weapons for rebels.

These natures are described as degrading not because they are intrinsically perverse but because they are the anchors of the all-encompassing degradation in the depths of subjectivity, where they are perpetuated and disguised by adopting normal, modern, or progressive physiognomies. This desensitizes any sense of collapse, obscures an understanding of the reality of the world, and supports permissiveness toward and complicity with the immeasurable spirit of profit that has nearly no restraints or resistance in ensuring that its interests prevail.

The degrading natures that underlie faith in civilization's progress are, even for the majority that is severely damaged by the prevailing order, insufficient to explain this widespread and rooted belief. In that respect, it is essential to realize that in our current form of civilization, "the societies of control" (not of knowledge as has been established) have been developed as a condition to preserve the status quo of control and inequality concerning growing discontent, resistance, or rebellion by the affected majority. This control is exercised through three mechanisms:

1)The media, including print, electronic, computer platforms, and social networks, where dominant interests prevail. The media control consciences through incessant waves of disinformation that distorts events; destabilizing, intensifying prejudices, inciting violence, and generating hope, fondness, phobias, fears; and, most importantly, fabricating realities that "make up" moral and social degradation or conceal the roots of the problem we suffer: the dominance of unlimited for-profit interests.

2) The content created by the enormous and diverse sports enterprise where fans are removed from the outside world in environments conducive to the depressurization of explosive affective responsibility that in other spaces would be seriously threatening or dangerous, the undercurrent of which is the accumulation of disagreements, frustrations, anxieties, or discontent caused by prevailing inhospitable and stressful environments.
3) Scholars who, by reproducing dominant ideas in various social workspaces (including scientific work), contribute to highly effective control because they escape the conscience of the victims, given that these predominant ideas do not follow a supposed superiority over alternative ideas but to their direct or indirect harmony with the dominant unlimited for-profit interests when supporting or concealing them ${ }^{8}$.

Since the effectiveness of control is directly related to its "invisibility," favorable or justified perceptions related to the current reality are promoted. It is experienced as the only possible reality, which is unyielding; thus, the primary challenge of life is to adapt. These perceptions convince people that the hardships, discomforts, and dissatisfactions that we suffer are simply rough patches - transitory - as long as our technological civilization recovers from its crisis to "continue its unstoppable, rising progress."

\section{Modern science}

Today, what we understand, accept, admire, and emulate as modern science, a prominent component of the widespread MWP in the case of countries that are victims of colonialism is the result of a long and painful process of inculcation by the dominant culture. Its manifestations and repercussions have remained after the formal independence of the colonized countries; modern science is a point of arrival for what was at the beginning a violent imposition on indigenous peoples that discredited and suppressed local, traditional, and ancestral knowledge (epistemicide according to Boaventura de S. Santos). Thus, modern science is not universal because of its supposed intrinsic superiority over other knowledge, but rather because of the unquestionable power that imposed it as such. As an objection to the explicit justification of the universality of modern science, among an immense diversity of coexisting knowledge (many of which are invisible or excluded by modern science) comes this revealing conflict. On the one hand, the peak of scientific knowledge is the worthiest of credit for the majority. It is a task for legions of researchers in all macro and micro spaces, with vigorous, vast, and diversified development in all disciplines and subdisciplines, with a progressive influence on how populations live; it is a depository for the generalized confidence in reaching higher forms of life and a better world. On the other hand, its coincidence with the collapse of civilization has been elaborated above. What can be inferred from such a coincidence? Serious questioning of the supposed epistemic superiority of science 
is needed because it is unacceptable that the most recognized, valued, and substantial knowledge, held to be real and valid, is seen as mostly harmless toward the degrading forces that overwhelm us or it is indifferent to the urgency of counteracting or weakening them. Furthermore, it is an unappealable judge that excludes transgressor knowledge from scientific norms and acceptability. In other words, the myriad scientific facts that occur in all areas are ignored or, worse, concealed and accomplices to the dominance of unlimited for-profit interests and their representatives that destroy civilization and devastate the planet.

To summarize, there are no compelling reasons, neither epistemic nor for social progress, that justify the universality of modern science because its incomplete knowledge over the last century, far from improving the spiritual, moral, and sociability aspects of the human condition and working toward a more hospitable world, has contemporized with the degradation, paving the way for the collapse of the environment and civilization. As pointed out earlier, the background is political. With its successive colonial empires that encompassed all continents, the Eurocentric hegemonic power has shaped science to respond to the growing requirements of capitalist development for the sake of supremacy, effectively imposing the universality of modern science that entails the power to disqualify nonscientific knowledge. Minimizing the benefits of modern science and its limits of validity is of urgent importance.

\section{Reductionist empiricism}

Given that the development of science was dependent on capitalist expansion and it complied with the imperialist needs of domination (economic, political, and ideological), it is clear why the process of degradation has been ignored; it is invisible to scientists whose knowledge is an organic part of the driving forces of such development. Now, we must scrutinize the reasons for such blindness or neglect in facing degradation, for which it is necessary to understand the epistemological logic that underlies modern science, which has two components, empiricism, and reductionism. Although both concepts are interwoven, they are analyzed separately for reasons of clarity.

a)Empiricism, which has a long history and succession of trends ${ }^{12}$, can be summarized in two assumptions: "experience is the source of all knowledge" and "the criterion for knowledge to be scientific lies in its methodical verification." These assumptions have been simplified (and trivialized) here: "the important thing is to generate reproducible objective facts through canonical experimental settings," where hypotheses have become dispensable since scientific facts expressed mathematically are a vital input of innovation and technological development. They are decisive for success in competition for market control and opportunities for companies to grow and expand. Besides, the priority is given to social control and domination technologies (i.e., military, space, computing, "smart" robotics, and medical). Today, science and technology are two sides of the same coin; hence, scientific contributions that do not result in new technology are regarded as useless and irrelevant or rejected, ignored, or discouraged. The refrain "a nation's sovereignty and self-determination depend on its degree of scientific and technological development," is a halftruth because the priority given to technological development is imposed by transnational corporations within hegemonic countries according to their profitability. Thus, by incessantly recolonizing with new technologies, corporations extract or vast direct resources abroad, reinforce their submission, and prevent autonomous development - all of which undermine or void sovereignty and self-determination. Further, equating social progress with technological development is foolish because it is guided by profit at all costs. Their real priorities (not explicit and covert) are to ignite a desire for unrestrained consumption by creating unavoidable needs (from possessing the most lethal weapons to the latest iPhone) and generating a dependency and addiction for newness. For this reason, "ultramodern" technologies (robotics, artificial intelligence) are taking over the exercise of skills and abilities from us because they tend to "atrophy due to lack of use" and affecting our ways of responding to existential difficulties by distorting how we coexist.

All this involves the delegation of initiatives, psychomotor skills, creativity, inventiveness, and even emotional support from loved ones. In the words of Bauman"13: "we no longer develop techniques to do what we want to do. Instead, we only select things to do because there is technology to do them." We must be aware of the implacable logic behind all successful technological development: to primarily satisfy interests in profit and to operate as a means of social control in the service of domination. In this regard, the "more intelligent" the technologies, the more they are profitable, as they boost consumer desire and require reciprocal operators: "less intelligent," increasingly thoughtless, dull, and dependent machines, which are more easily manipulated by the media. 
b) Reductionism ${ }^{14}$ can be summarized based on these premises: "the whole is no more than the sum of the parts" and "a complex system can only be explained by reducing it to its fundamental parts". In this regard, the reduction is confirmed as necessary and sufficient to solve knowledge problems. For example, biological processes can be reduced to the chemical movement of matter, and the laws of chemistry are explained using atomic physics.

The prevailing discourse states that the foundations of all truth about living beings are the knowledge of hard sciences (physics and chemistry); this reductionist thinking considers molecular biology as the pure science of life, hence its role when it comes to ground progress in these fields. It is essential to distinguish between reductionism and reduction. The first refers to the logical plane that favors the hard sciences in the causal interpretation of biological, psychological, or social phenomena. The second refers to the empirical plane: methodical procedures of observation and experimentation that isolate the events of interest from a more complex context, where settings in controlled situations allow the selective demonstration of some and the exclusion of all others. In other words, a procedural reduction is not necessarily reductionist because it can turn to an appropriate order of interpretation (biological) for the vital phenomena that it isolates and observes.

\section{The scientific task}

Under reductionist empiricism, the role of ideas in the knowledge of life is devalued or trivialized, which explains why the truly biological space is today occupied by a vast number of objective, aseptic, reproducible facts of a physical-chemical nature, considered independent of the researchers' prejudices. Theories and concepts referring to vital phenomena tend to be absent because researchers perceive them as subjective deviations, illegitimate interference, and alertness to potentially misrepresented "self-evident facts." This empiricist and reductionist conviction of science, which schooling reproduces on the social plane, is the origin of the current forms of division of labor. Such exclusionary specialization penetrates all workspaces to the degree that, with infrequent exceptions, it is the only visible form of specialized work. This specialization progressively limits the cognitive interests of specialists to increasingly restricted domains of experience and, conversely, favors ignorance or cognitive indifference toward an increasing variety of domains, regardless of whether they are close, related, or complementary. In exclusionary specialization, the restricted core of cognitive interest activities tends to be dissociated with and isolated from the historical, social, political, or environmental context in which specialists find themselves. They do not perceive this context as an "object of inquiry;" even though they come into contact with a disturbing external world, they do so by leaving aside their attitudes, powers, and cognitive interests. Even specialists with the highest academic training are vulnerable to media manipulation because of the many subjects that they are indifferent to, including events that shake the collective conscience and affect them as inhabitants of a devastated planet. In this way, considering contextual knowledge to not be their responsibility, in their eagerness, they tend to overestimate the technological aspect while facing their cognitive challenges and making progress in the knowledge of their limited scope of the inquiry, dismissing integrative, or explanatory ideas beyond the mechanistic causality ${ }^{15}$.

Another consequence of exclusionary specialization in scientific endeavors is the fragmentation, dispersion, and cognitive isolation of disciplines and subdisciplines, which results in the "vaccination" of researchers against general ideas that include and hierarchize a variety of macro and micro-events. They experience the vast scientific domain as a scattered archipelago where the only important thing is the field of inquiry. When integrative and explanatory ideas have been absent from scientific thought that only recognizes mechanistic causality as a formula to validate associations between events, the connections, interdependencies, and hierarchical relations between different events in the natural and human world are obscured. Not only ignores or denies certain phenomena but also disqualifies theoretical integrative attempts as speculative or lacking "scientific evidence." Here lies the origin of doubt or denial concerning the collapse of civilization by many scientists: there are no scientific confirmations; their insensitivity about the collapse is aggravated, given the vulnerability to media manipulation, which makes it invisible. Thus, the present day's predominant interpretation is instilled in the conscience of victims: "a painful but necessary phase of our rising path of progress".

The exclusionary specialization also explains the ineffectiveness of modern science in the presence of degradation: it is because of attitudes such as "it is not perceived" or "it does not concern us because it is a matter for other specialists." This attitude makes it impossible for the "scientific community" to gather and connect around the creative potential to clarify the 
problems that underlie "cultural discontent," to organize and cooperate under new forms of division of labor, to mobilize with clarity of vision collectively, and to design combined and sequential large-scale strategies to weaken or counteract degrading forces.

To summarize, it can be said that the effective role of scientific knowledge at this time is far from being that of a guarantor of overcoming the human condition. The imperatives of power and control that condition and shape scientific knowledge on the backs of scientists has serious consequences: it is worsened by enlightening and integrating ideas. It is aimed at the useful and pragmatic; it is governed by the profitable; it has lost their critical and liberating edge; it ignores the misuse of its contributions; and it is distorted by biased and self-interested donations and has become a powerful instrument of control, a mirage of progress ${ }^{2}$.

A serious problem in modern science lies in the assumption of universality and monopoly of true and valid knowledge. Two concepts are compared regarding the types of relationship between humans and nature, implicit in modern science and inspired by the traditional knowledge of indigenous peoples who are the victims of colonization: (a) modern science imperceptibly inherited the basic monotheistic principle (anthropocentric symbol) that "man, the height of creation, has the power to serve and subject nature to his will." From the beginning, in its questioning and inquisitive thoughts, science ignored the abusive and destructive relationship of humans with nature, implicitly assuming and avoiding delicate issues (such as confronting intolerance or ecclesiastical condemnation). This appeasement was "justified" for a long time by classifying matters as "metaphysical" according to triumphant empiricism and, therefore, excluding them from the realm of scientific problems. However, this neglect favored the continuation of the above-mentioned principles in the collective unconscious of researchers; questions regarding the atrocities perpetrated on nature were suppressed ("we are not responsible for that"). Given the authority of science, a "free rein" was given to the destructive forces (which today are greater than the productive ones) that have caused absolute pollution, the devastation of ecosystems, and weakening of the biodiversity and viability of life, covered in that "permissive oversight" of universal science. (b) In contrast, knowledge of indigenous peoples who survived the epistemicide was preserved across generations that were educated in the "metaphysics" of Mother Earth, giver of life and involved resisting violence, looting, and dispossession; they learned to revere her, take care of her, call upon her, calm her, and live in harmony with her. Today, these cultures represent a moral reserve in our degraded species; the protection of the non-anthropocentric concepts of nature echoed in $\mathrm{J}$ Lovelock's proposals ${ }^{\mathrm{b}, 16,17}$. These concepts have given rise to productive agricultural practices that are relevant to ecological circumstances, preserving the environment, and providing viable food options for the future, avoiding the devastation caused by the agribusiness.

Environmental collapse and irreversible global warming affect everything. It makes our commonplace of residence inhospitable and eliminates the possibility of a dignified life for future inhabitants (the recent rise of the young people in Europe with an irrefutable reproach to adults and politicians for their passivity concerning climate change: "studying for a future that will not exist does not make sense" must be noted). It is the most visible and forceful evidence of the unjustified and inappropriate nature of modern science as the monopolistic holder of authentic and valid knowledge. It deems modern science to be unlawful, for it has not only been ineffective but also has been cooperative with an enormous problem. This illegitimacy is because it suppressed incompatible ancestral knowledge without the least scrutiny; it has been shaped by for-profit interests; and it has coexisted peacefully with imminent collapse; scattered and disconnected scientific knowledge has avoided facing the human condition (deeming it as a metaphysical matter). It has increasingly been reduced to "inputting" technological innovation and operates predominantly as a powerful device for social control and a decoy of progress.

\section{Research and health care}

To continue, a digression to compare the prevailing idea of social progress with economic development is discussed. It is assumed that the solutions to the severe problems are within reach of science and technology, and it is a matter of time until the appropriate technologies arrive to overcome them. This idea of (material) progress overlooks the political roots of problems: asymmetries of power between social classes and the origins

\footnotetext{
b James Lovelock's Gaia theory, which appeared at the beginning of the 1970s, was of a transdisciplinary nature with solid scientific foundations (not confirmations) and a great unifying and explanatory power of life. It represents a kind of vindication for "Mother Earth," because it reconstructs, argues, and justifies that planetary life as a whole creates its own conditions of permanence and development and establishes that the effective role of humans in the order of life is that of the "original plague," the opposite of that implied by biblical teachings. As would be expected, this theory is still questioned and disqualified by modern reductionist science.
} 
of inequalities (for the centers of power, the ruin of civilization is the "forced and painful" phase of the path of progress). This idea can be held inversely: the core of progress is the spiritual, intellectual, moral, and social overcoming of the human condition in reciprocity with nature ${ }^{18}$. Consequently, this progress will only take place when collective energies are organized. Furthermore, when collective effort aspires toward inclusive, participatory, deliberative, diverse, egalitarian, fair, open, and supportive societies based on the respect for and the promotion of human rights and all forms of life (assuring care for the ecosystem), where dignified, reflective, fruitful, fraternal, biophilic, satisfying, gratifying, moderate, and serene lifestyles flourish. Although this utopia is in a feasible horizon (it alludes to qualities exhibited by groups or communities at different times in history), it moves away because the domination of for-profit interests perpetuates degrading natures. Through the means of disinformation and persuasion and by idealizing technology, technofetishism is erected as the majority religion that congregates its faithful (addicted consumers) through insatiable longings and unsatisfied desire rather than through the possession of novelties ${ }^{19}$.

Regarding science and health, the increasing dependence of specialized work on technology is to the extent that what is most valued in the performance of a variety of specialized tasks (including research) is the instrumental control of techniques, procedures, and state-ofthe-art technological equipment. Thus, by focusing cognitively on operating machines or designing experimental assemblies, specialists are becoming an appendix of the machine who must adapt (under penalty of exclusion) to the changing operational requirements of technologies, which are constantly renewed. In medical practice, laboratory studies and, formerly, office auxiliary diagnostics related to the patient's disease now reverse their role, and it is the doctor who is becoming an assistant to all-powerful technology.

\section{Diseases}

Disease, the core of research and healthcare, has been a source of fear, uncertainty, worry, and anxiety since the dawn of human life when facing the unfailing presence of discontent. In addition, the disease involves physical or mental suffering, limitations in performance of tasks or self-reliance, and issues with living together or premature death, which groups learned to recognize, value, differentiate, counteract, and care for according to their myths, traditions, and opportunities. In short, based on colonialism that imposed the MWP and modern science, the ontological idea of disease prevailed as a strange anomaly or foreign adversity (external) to human nature and, ultimately, as an independent and autonomous body ${ }^{20}$. Behind this idea lies anthropocentric thinking typical of monotheisms that could be expressed in this way: "we are a culminating and perfect creation of God; our ailments are imperfections caused by influences or interferences of a threatening exterior or by inscrutable plans by the Supreme Being." Over time, due to reductionist empiricism, the anomaly became a strange and foreign object; that is, the objectification of disease that allowed for the justification of the unquestionable objectivity of scientific research in this regard.

A reciprocal concept of disease that survived colonialism and was preserved in the Far East and some original cultures can be stated as "a change in internal harmony or the continuous flow of vital energy (intrinsic)," attributed to transgressions or disagreements with nature ${ }^{20}$. Here, the underlying thought is opposite to the anthropocentric one: "we are part of the cosmos, of "Mother Earth." Our sacred duty is to respect her, take care of her, and live in harmony with her under the penalty of misfortune".

It is clarified that the proposed polarity to characterize the disease, although it suffers from simplification and schematism, defines a broad spectrum of possible intermediate variants (what we have inherited are different hybrids) and, most importantly, at both extremes, they correspond to inverse ways of confronting disease. With "foreign and external objects," strategies focus on diminishing, counteracting, or eliminating the disease, hence the name suppressive medicine ${ }^{20}$. Concerning the "internal lack of harmony" paradigm, the objective of the study is each individuality with its constellation of symptoms and circumstances; thus, the healing strategies are reversed: individualized strategies are used to strengthen and revive each individuality to restore harmony with its environment. This is known as stimulant medicine ${ }^{20}$.

For modern science, both patient's individuality and the individualization of the treatment (stimulus) belong to the "metaphysical" plane (inaccessible to direct verification and, above all, to intersubjective confirmation that denies individuality and invalidates therapeutic individualization). Therefore, it cannot be part of a science or a cause for scientific inquiry; hence, it is disqualified and excluded from the study. For suppressive medicine, the disease in question (an abstract, generic, and autonomous organism entity), which can be characterized in physicochemical terms based on statistical references and explained through mechanistic causality, is paradigmatic of the scientific objective. It constitutes a crumbly problem susceptible to the exact and precise 
measurement for empirical confirmation to choose the most effective treatment ${ }^{c}$.

Stimulant medicine does not seek circumscribed influences (physical-chemical plane) but rather diffuse, systemic, and individualized ones because its basis is to characterize the lack of harmony present in each irreducible individuality to select the relevant treatment (individualized) to restore it (clearly, it does not necessarily achieve it). These premises clash with the criteria of scientific nature: "valid knowledge objectives are collectivities with the same disease and exposed to the same treatment." This gives rise to the practical impossibility of several alternative medicines to support scientific arguments related to curative effectiveness because the prevailing criteria deny the possibility of individualization of treatment ${ }^{20}$, which means that, to obtain a scientific endorsement, they are forced to "denaturalize."

Here is another (late) sequel of the epistemicide perpetrated by modern science, which refutes its universality: it imposes a narrow criterion of validity that is not relevant to the qualitatively different objectives of alternative medicines that embody stimulant medicine (particularly herbalists who transfer wisdom over millennia). This leads them to be disqualified in favor of "the health industry," while struggling with poor profitability and not collaborating with big businesses that perpetuate "endless agony and uneasy death." Thus, by reporting the anti-scientific nature of healing traditions described as naive and obscurantist based on myths immune to scientific validation, modern science is not seen as a superior episteme with a self-critical calling, an open mind, or openness to review the relevance of its methods (according to the circumstances). It is seen as a representative of domination, exhibiting a core principle that is impossible to question or minimize based on the limits of the applicability of its validity criteria. It is reluctant to investigate "knowledge that withstood time" based on proper parameters. Thus, health regulatory authorities deprive people of current and potential future benefits of their traditional therapeutic resources.

\section{The medicalization of social life}

In the health sphere, we find another objection to the universal nature of modern science: the progressive

\footnotetext{
c With regard to clinical research that investigates disease through the patient's account, signs, and symptoms, although it mitigates reductionism, at the time of acting, it cannot escape the idea of chronic disease as an independent and autonomous body, rejecting the famous motto: "there are no diseases, only sick people."
}

medicalization of societies, where the incessant assimilation of scientific truths (partial and fragmentary), far from contributing to dignified, satisfactory, fraternal, sober, or serene ways of life, raise a growing dependence, anxiety, and unrest ${ }^{21}$. Thus, the universality of scientific knowledge is illegitimate because it does not hold to its merits but rather to its agreement with the domination of for-profit interests (complicity with health corporations) and their contribution, through medicalization, in controlling minds and bodies by absorbing them and rendering them unconscious, permissive, or complicit with degradation. This "social anesthesia" arises in several ways:

1) The obsession with health and the fear of illness become perpetual tensions and frustrations that polarize human life and take the population's attention away from the collapse of civilization that affects everyone.

2) Faith in science and technology as a guarantee of profit and guidance to achieve better ways of life prevents us from perceiving medicalization as a historical condition set by the health industry. In this condition, "truths" are spread to obtaining high-profit rates, and the market is controlled using advertising techniques that manipulate users and providers with high doses of false security, induced needs, and unfounded expectations that underlie the compulsive consumption of "everything good for your health."

3) Researchers from academic and corporate institutions are forced to reduce their knowledge about the input-process of innovations. First, they are persuaded by priority projects' funding from the industry that conditions the type of problems to be researched, the way to approach them, and the technology involved in their implementation; second, they are focused on capitalizing on the inputs in promising innovations for business. In both situations, the freedom of research is false: the search for knowledge has been supplanted by the search for funding, and the researcher, a victim of media manipulation, disregards events in the outside world that are of concern.

By convincing people that their primary concern is to stay healthy and their responsibilities are to take care of their health in the hope of a good life ${ }^{21}$, medicalization has highly effective control. By polarizing the population's attention, the unfair order that perpetuates unhealthy and pathogenic environments, which contain the root of the health problems, becomes invisible ${ }^{21}$.

Modern science perpetuates and renews the extractive and plundering colonialism that indoctrinates and persuades communities in subordinate countries to join the great business of science, only for good. The conditions of accepting the demands and standards of scientific 
quality are based on for the following reasons: to prioritize border problems (high profitability that supplants the priorities of the colonized); to implement canonical experimental settings with state-of-the-art technologies (importing equipment and materials of rapid expiration and increasing costs); to use the means of disseminating "good science:" high-impact specialized journals (only for colleagues, with meager epistemic contributions, with little social relevance, and a higher cost); and quantitative performance evaluation criteria: articles, financing, or patents (directly and proportionally related to profitability), that is an entire invisible framework of coercion, subjection, and exaction, whose transmission belts are local regulatory agencies of science! Neocolonialism means a high degree of bloodletting that funds the colonizer. In the robust health industry and its subsidiary health research, pressing domestic problems usually manage to escape the conscience of scientists convinced to be the leading figures of universal science.

\section{Epilogue}

Colonialism is a historical aspect bound to penetrate the current reality of colonized and dependent societies as marked inequalities and in their relations and attitudes of economic and cultural subordination with respect to dominant countries. Without this understanding, it is impossible to avoid the fabricated realities propagated through the means of disinformation at the service of the domination of for-profit interests and their representatives. Drawing from colonialism, it can be clarified that the empire of the MWP and modern science does not have the supposed intrinsic superiority over other worldviews and knowledge but rather is a recent result of an imposition of colonial power to the subjugated cultures that were universalized.

This work's argument focuses on specifying objections to the universality and monopoly of the true and valid knowledge that modern science holds, with the following standing out as predominant non-absolute trends:

a) Its peaceful coexistence with degradation and its ineffectiveness against environmental catastrophe

b) Its collusion with industry in the devastation of the Earth, coupled with the dejection of indigenous traditions that learned to harmonize with nature and practice cultivation while respecting the environment

c) Its key role as an input process of innovating social control industries (i.e., military, space, computing, and media)

d) Its prominence in the exclusion of ancestral knowledge that has withstood the test of time and includes benefits and opportunities that must be researched (stimulating medicine) in the health field

e) Its submission to the powerful health industry that has resulted in the medicalization of human life that immerse population in perpetual uncertainty, anxiety, and restlessness

f) Its neocolonialist role that, by imposing "the priorities of science," supplants and hides those of subordinated countries and subtracts substantial resources to the detriment of social policies and programs.

However, the most significant objection to universality derives from its reductionist empiricism that conditions the scientists to acknowledge the practical impossibility of an enlightening and unifying (not summative) knowledge of the current world in two respects: who are we?, an anthropocentric humanity that preys on nature, warlike with uncontrollable ethnocentrisms that seek domination supremacy. Moreover, where are we?, a historical phase of extreme degradation of human and planetary life in civilizational and environmental collapse. This limitation prevents them from realizing their subjugation to unlimited for-profit interests, the root of the degradation ("nobody knows whom they work for"). Neglecting the reduction of scientific knowledge to the input process of cutting-edge technological innovations and planned obsolescence, they become critical accomplices in the genesis of deleterious garbage and waste (from plastics to satellites) that cause harmful and silent planetary devastation (a disguised ecocidal science).

Awareness of the current situation is sine qua non to distance oneself from degrading natures to take responsibility for the future of a devastated planet and a civilization in ruins and to rethink, if necessary, the collective role that we play in the search for a hospitable world d. Concerning science, it is urgent to question its

\footnotetext{
$\mathrm{d}$ In this regard, the reductionism that prevails in all social tasks and, in particular, that of various organizations such as those that protect and defend the environment or safeguard and promote human rights, causes its strategies for action to be focused on limited issues (the goal to which they dedicate their efforts). They tend to wear away if they are not connected and strengthened with other organizations of various kinds and, as the target of their actions are "the symptoms" and not "the etiopathogenesis of the disease", the domination of unlimited for-profit interests in absolute degradation and civilizational collapse. This generally remains untouched or out of focus, the bold efforts of these organizations will be tinged with immediacy, loaded with frustrations, and of little relevance in the long term (sabotaged or crushed by an absolute, relentless power). It would then address seeking partnerships with the diverse, synergistic integrations of increasing scope capable of weakening, on various fronts, the domination of for-profit interests that are an unavoidable situation for effective progress in each specific field of action.
} 
idolized truths and its "aseptic neutrality". To report its dependence and complicity with the darkest and most destructive forces in history; to recognize the overreaching of its criteria of epistemic, methodical, and procedural validity; to criticize its dogmatic authoritarianism that excludes valuable knowledge in the fight against absolute degradation; to minimize it as the driving force of progress in the search for a hospitable world for all forms of life; and to stir up the scientific habitus inciting it to critique the logic of thinking and dominant ideas.

For any opinion, this work has attempted to discuss possible options using an inclusive approach through a transdisciplinary point of view that is rarely tolerated by official science. Furthermore, to clarify the roots of the great evils that we suffer from, with the understanding that in human affairs, the guiding thread for enlightenment is identifying unequal power relations and the exercise of domination ${ }^{22,23}$.

As Boaventura de Sousa Santos observed: "We make history to the extent that we resist what history makes of us."

\section{Conflicts of interest}

The author declares no conflicts of interest.

\section{Funding}

None.

\section{References}

1. Santos BS, Meneses MP. Introducción. In: Santos BS, Meneses, MP, editors. Epistemologías del Sur (Perspectivas). Madrid: Ediciones Akal; 2014. p. 15.
2. Viniegra-Velázquez L. El orden cultural, la enfermedad y el cuidado de la salud. Bol Med Hosp Infant Mex. 2017;74:397-406.

3. Santos BS. Más allá del pensamiento abismal: de las líneas globales a una ecología de saberes. In: Santos BS, Meneses, MP, editors. Epistemologías del Sur (Perspectivas). Madrid: Ediciones Akal; 2014. p. 48.

4. Quijano A. Colonialidad del poder y clasificación social. In: Santos BS, Meneses, MP, editors. Epistemologías del Sur (Perspectivas). Madrid: Ediciones Akal; 2014. p. 91.

5. Carnoy M. Teorías del Colonialismo. La Educación Como Imperialismo Cultural. México: Siglo XXI Editores; 1976. p. 65-77.

6. Chomsky N. Secretos, Mentiras y Democracia. México: Siglo XXI Editores; 1997.

7. Chomsky N. Estados Canallas: el Imperio de la Fuerza en Los Asuntos Mundiales. Barcelona: Ediciones Paidós Ibérica; 2001.

8. Viniegra-Velázquez L. Aptitudes y educación médica en tiempos oscuros. Parte I. Invest Educ Med. 2017;6:272-80.

9. Chomsky N. El Terror Como Política Exterior de Estados Unidos. Buenos Aires: Libros del Zorzal; 2001.

10. Viniegra-Velázquez L. La educación en nuestro tiempo: ¿competencia o aptitud? El caso de la medicina. Parte I. Bol Med Hosp Infant Mex. 2017;74:164-72.

11. Bauman $Z$, editor. La vida líquida moderna y susmiedos. In: Tiempos Líquidos. Vivir en Una Época de Incertidumbre. México: Tusquets Editores; 2013. p. 13-8.

12. Honderich T. Empiricism. In: Honderich T, editor. The Oxford Companion of Philosophy. New York: Oxford University Press; 2005. p. 242-5.

13. Bauman Z. Tiempos Líquidos. Vivir en Una Época de Incertidumbre. México: Tusquets Editores; 2008. p. 154-5.

14. Honderich T. Reductionism. In: Honderich T, editor. The Oxford Companion of Philosophy. New York: Oxford University Press; 2005. p. 793-5.

15. Viniegra-Velázquez L. Crítica de la causalidad mecanicista en las ciencias de la vida. Bol Med Hosp Infant Mex. 2014;71:252-7.

16. Lovelock J. Gaia, Una Nueva Visión de la Vida Sobre la Tierra. España: Herman Blume Ediciones; 1983.

17. Lovelock J. Las Edades de Gaia. Una Biografía de Nuestroplaneta Vivo. Barcelona: Tusquets Editores; 2000.

18. Viniegra L. El Progreso y la Educación. Educación y Crítica. México: Editorial Paidós Mexicana; 2002. p. 83-103.

19. Viniegra-Velázquez L. El fetichismo de la tecnología. Rev Invest Clin. 2000;52:569-80.

20. Viniegra-Velázquez L. Medicina supresora y medicina estimulante: una mirada penetrante de la práctica médica. Bol Med Hosp Infant Mex. 2018;75:267-78.

21. Viniegra-Velázquez L. El bienvivir: ¿cuidado de la salud o proyecto vital? Parte I. Bol Med Hosp Infant Mex. 2016;73:139-46.

22. Poulantzas N. Poder Político y Clases Sociales en el Estado Capitalista. México: Siglo XXI Editores; 1974. p. 284-9.

23. Poulantzas N. Las Clases Sociales en el Capitalismo Actual. México: Siglo XXI Editores; 1976. p. 12-35. 